University of Montana

ScholarWorks at University of Montana

8-2005

\title{
Human Activity Mediates a Trophic Cascade Caused by Wolves
}

\author{
Mark Hebblewhite \\ University of Montana - Missoula, mark.hebblewhite@umontana.edu \\ Clifford A. White \\ Parks Canada, Banff National Park \\ Clifford G. Nietvelt \\ University of Alberta \\ John A. McKenzie \\ University of Guelph \\ Tomas E. Hurd \\ Parks Canada \\ See next page for additional authors \\ Follow this and additional works at: https://scholarworks.umt.edu/biosci_pubs \\ Part of the Biology Commons \\ Let us know how access to this document benefits you.
}

\section{Recommended Citation}

Hebblewhite, Mark; White, Clifford A.; Nietvelt, Clifford G.; McKenzie, John A.; Hurd, Tomas E.; Fryxell, John M.; Bayley, Suzanne E.; and Paquet, Paul C., "Human Activity Mediates a Trophic Cascade Caused by Wolves" (2005). Biological Sciences Faculty Publications. 288.

https://scholarworks.umt.edu/biosci_pubs/288

This Article is brought to you for free and open access by the Biological Sciences at ScholarWorks at University of Montana. It has been accepted for inclusion in Biological Sciences Faculty Publications by an authorized administrator of ScholarWorks at University of Montana. For more information, please contact

scholarworks@mso.umt.edu. 


\section{Authors}

Mark Hebblewhite, Clifford A. White, Clifford G. Nietvelt, John A. McKenzie, Tomas E. Hurd, John M.

Fryxell, Suzanne E. Bayley, and Paul C. Paquet 


\title{
HUMAN ACTIVITY MEDIATES A TROPHIC CASCADE CAUSED BY WOLVES
}

\author{
Mark Hebblewhite, ${ }^{1,7}$ Clifford A. White, ${ }^{2,3}$ Clifford G. Nietvelt,${ }^{1}$ John A. McKenzie,, 4 \\ Tomas E. Hurd, ${ }^{2}$ John M. Fryxell, ${ }^{4}$ Suzanne E. Bayley, ${ }^{1}$ and Paul C. Paquet ${ }^{6}$ \\ ${ }^{1}$ Department of Biological Sciences, University of Alberta, Edmonton, Alberta, T6G 2E9 Canada \\ ${ }^{2}$ Parks Canada, P.O. Box 900, Banff, Alberta T1L 1 K2 Canada \\ ${ }^{3}$ Department of Forest Sciences, University of British Columbia, Vancouver, British Columbia V6T 1 Z4 Canada \\ ${ }^{4}$ Department of Zoology, University of Guelph, Guelph, Ontario N1G 2 WI Canada \\ ${ }_{5}^{5}$ National Parks Directorate, Parks Canada, 25 Eddy, Hull, Quebec K1A OM5 Canada \\ ${ }^{6}$ Faculty of Environmental Design, University of Calgary, Calgary, Alberta T2N IN4 Canada
}

\begin{abstract}
Experimental evidence of trophic cascades initiated by large vertebrate predators is rare in terrestrial ecosystems. A serendipitous natural experiment provided an opportunity to test the trophic cascade hypothesis for wolves (Canis lupus) in Banff National Park, Canada. The first wolf pack recolonized the Bow Valley of Banff National Park in 1986. High human activity partially excluded wolves from one area of the Bow Valley (low-wolf area), whereas wolves made full use of an adjacent area (high-wolf area). We investigated the effects of differential wolf predation between these two areas on elk (Cervus elaphus) population density, adult female survival, and calf recruitment; aspen (Populus tremuloides) recruitment and browse intensity; willow (Salix spp.) production, browsing intensity, and net growth; beaver (Castor canadensis) density; and riparian songbird diversity, evenness, and abundance. We compared effects of recolonizing wolves on these response variables using the log response ratio between the low-wolf and high-wolf treatments. Elk population density diverged over time in the two treatments, such that elk were an order of magnitude more numerous in the low-wolf area compared to the high-wolf area at the end of the study. Annual survival of adult female elk was $62 \%$ in the high-wolf area vs. $89 \%$ in the low-wolf area. Annual recruitment of calves was $15 \%$ in the high-wolf area vs. $27 \%$ without wolves. Wolf exclusion decreased aspen recruitment, willow production, and increased willow and aspen browsing intensity. Beaver lodge density was negatively correlated to elk density, and elk herbivory had an indirect negative effect on riparian songbird diversity and abundance. These alternating patterns across trophic levels support the wolf-caused trophic cascade hypothesis. Human activity strongly mediated these cascade effects, through a depressing effect on habitat use by wolves. Thus, conservation strategies based on the trophic importance of large carnivores have increased support in terrestrial ecosystems.
\end{abstract}

Key words: carnivore; community ecology; conservation; herbivory; human activity; park management; predation; predator exclusion; trophic cascade; wolf.

\section{INTRODUCTION}

Predators can influence community structure and dynamics through direct lethal effects on prey (Paine 1969, Polis and Strong 1996) and indirect behavioral effects that alter prey distribution and habitat selection (Lima and Dill 1990, Schmitz et al. 1997). "Topdown" effects by predators on prey populations can indirectly increase plant biomass by reducing herbivore density and altering herbivore behavior (Terborgh et al. 2001). These top-down effects of predators through trophic levels are known as trophic cascades (Carpenter et al. 1985). Recent efforts in ecology have uncovered trophic cascades in diverse ecological communities

Manuscript received 13 August 2004; accepted 10 January 2005. Corresponding Editor: S. W. Seagle.

${ }^{7}$ E-mail: mark.hebblewhite@ualberta.ca across a wide array of taxa (see reviews in Schmitz et al. [2000], and Shurin et al. [2002]).

The strength of trophic cascades varies across ecosystems due to variation in food web complexity, diversity, productivity, and indirect feedbacks, such as plant toxins that inhibit herbivory (Schmitz et al. 2000). Trophic cascades tend to be more common in aquatic systems and systems with low diversity and food web complexity (Polis and Strong 1996). Generally, the influence of predators on plant biomass in terrestrial systems is lower than aquatic systems (Shurin et al. 2002). Experimental evidence for trophic cascades in terrestrial systems comes largely from experiments on invertebrates such as ants, arthropods, with few vertebrate examples (Schmitz et al. 2000).

Trophic cascades, and the related concept of keystone species (Paine 1969, Power et al. 1996), have become enshrined in conservation biology as a ratio- 
nale and justification for conservation strategies focusing on vertebrate carnivores (Simberloff 1998, Carroll et al. 2001). Ecosystems without top predators are argued to have high herbivore densities with associated negative impacts on plant communities, leading to reductions in biodiversity (Terborgh et al. 1999). Recent carnivore reintroduction efforts (Fritts et al. 1997) and broad-scale conservation projects (Soulé and Terborgh 1999) highlight the conservation and management importance of trophic cascade theory. Park management plans often cite the key trophic role of predators as a rationale for carnivore conservation (Parks Canada 2000).

Experimental evidence of trophic cascades initiated by terrestrial vertebrate predators is rare in the literature (e.g., Schmitz et al. 2000, Shurin et al. 2002). The most compelling examples come from natural experiments in the tropics, such as Barro Colorado Island (Wright et al. 1994) and the Lago Guri Islands (Terborgh et al. 2001). Human creation of these islands from formerly contiguous tropical forests resulted in the loss of top predators such as jaguars (Panthera panthera). Monkey abundance increased dramatically on jaguar-free islands, with negative impacts on songbirds, ant diversity, and plant communities (Wright et al. 1994, Terborgh et al. 2001).

Experimental evidence of trophic cascades caused by terrestrial vertebrate predators in temperate ecosystems is more limited. Some experimental evidence comes from the lynx (Lynx Canadensis)-snowshoe hare (Lepus americanus) cycle investigated in a largescale partial predator exclusion experiment (Krebs et al. 1995). In this system, exclusion of predators led to a doubling of prey density: However, food supplementation led to a three-fold increase in prey. Strong bottom-up effects weaken arguments for strong top-down effects in this experiment. Recent attempts to infer topdown effects of predators have drawn on comparisons across areas with and without predators (Berger et al. 2001), or correlative studies of vegetation response following predator restoration (Ripple et al. 2001, Ripple and Beschta 2003). One of the most important examples of temperate terrestrial trophic cascades is the wolf (Canis lupus)-moose (Alces alces)-balsam fir (Abies balsamifera) system on Isle Royale (McLaren and Peterson 1994). Despite its importance, experimental ecologists view cause and effect in the Isle Royale system as somewhat unclear because of the studies correlative nature (Schmitz et al. 2000). Regardless, ecologists all agree experimental evidence from temperate terrestrial systems is urgently needed to justify largescale conservation plans (Terborgh et al. 1999). Wolf recolonization through dispersal and recolonization may provide feasible experimental conditions to test for trophic cascades.

Wolves naturally recolonized the Bow Valley of Banff National Park (BNP hereafter) in the mid-1980s through dispersal from contiguous populations to the north (Paquet et al. 1996). High human densities surrounding the townsite of Banff prevented full wolf recolonization, whereas wolves fully recovered in adjacent areas, presenting conditions for an experimental test of the trophic cascade hypothesis for wolves. We compared the effects of wolf exclusion on their predominant herbivore prey, elk (Cervus elaphus), as well as looking at the indirect effects of wolf exclusion on important food plants favored by elk, and other species that depend, in turn, on these plants. We compare differences between areas using log response ratios, an approach common in the community ecology and metaanalysis literature (Hedges et al. 1999, Schmitz et al. 2000), while accounting for temporal variation in responses that may be dynamic (i.e., elk density; Osenberg et al. 1997).

\section{STUdy AREA}

BNP is $6641 \mathrm{~km}^{2}$ in area and is located on the eastern slope of the continental divide in the front and main ranges of the Canadian Rocky Mountains $\left(51^{\circ} 15^{\prime} \mathrm{N}\right.$, $\left.116^{\circ} 30^{\prime} \mathrm{W}\right)$. The park has extreme mountainous topography (1400-3400 m). The climate is characterized by long, cold winters with infrequent warm weather caused by Chinook winds, and short, dry summers. Our study area focused on low-elevation winter range for elk in the Bow Valley. Valley bottoms are $2-5 \mathrm{~km}$ in width, and from 1350 to 1600 m elevation. The national railway and highway (Trans-Canada Highway, TCH) system, secondary roads, and human developments (ski resorts, golf courses) occupy the study area. The lowwolf area surrounds the town of Banff, whose human population is $\sim 10000$, and its associated development.

Vegetation is dominated by coniferous stands of lodgepole pine (Pinus contorta), Englemann spruce (Picea englemanni), and subalpine fir (Abies lasiocarpa) stands grading into alpine meadows at elevations above $2200 \mathrm{~m}$. Grassland, riparian, and deciduous trembling aspen communities are rare $(<5 \%$ of BNP; Holland and Coen 1983), but critical communities important for ungulate foraging. Riparian willow communities were dominated by Salix maccalliana, S. planifolia, S. bebbiana, and S. commutata. Holland and Coen (1983) describe the vegetation in detail. Six species of large herbivores exist in BNP: elk, white-tailed deer (Odocoileus virginanus), moose, mule deer $(O$. hemionus), bighorn sheep (Ovis canadensis), and mountain goat (Oreamnos americanus). Elk were the most abundant ungulate in BNP, comprising 40-70\% of the diet of wolves (Hebblewhite et al. 2004), followed by both deer species (10-30\%); whereas other species are rare or largely unavailable to wolves (i.e., sheep; Holroyd and Van Tighem 1983). Other predators included cougars (Felis concolour), coyotes (Canis latrans), grizzly bears (Ursus arctos), and black bears (Ursus americanus). However, wolves were the only species to recover from extirpation (Paquet et al. 1996). 
See Holland and Coen (1983) and Hebblewhite et al. (2002) for a more detailed description of the study area.

\section{Methods}

Wolves recolonized the Bow Valley in 1986, except for the central area surrounding the townsite of Banff. High human use of the central area greatly reduced wolf use (Paquet et al. 1996, Duke et al. 2001) and predation on elk (Hebblewhite et al. 2002; see Plate 1). In the adjacent western area, wolves have been present continuously since 1986, and in the eastern area since 1991. Thus, we considered the central area as the low-predation treatment (see Results) and eastern and western areas outside this as the high-wolf treatment. For the elk density data, the high-predation data correspond to the western area in Hebblewhite et al. (2002) where wolves were present during the entire time series.

\section{Wolf predation}

Hebblewhite et al. (2002, 2004) describe methods used to study predation by wolves in detail. Wolves were captured and radiocollared in summer using modified foot-hold traps and during winter using helicopter darting or netgunning (all capture, handling, and research methods approved under BNP Permit Number B-1994-29). Once radiocollared, wolves were tracked in the snow daily during winter months to estimate the numbers of wolves using each treatment area (number of wolves) and area-specific kill rates (elk/day/pack). We used total number of elk killed by wolves in each area (elk/day) instead of predator density because the total number of elk killed integrates the functional and numeric responses within each area (Messier 1994). Kill rates of elk (elk/day) were estimated in each area using a ratio-estimator during winter (Hebblewhite et al. 2004) and were compared using a $t$ test, after verifying kill rates were normally distributed (Hebblewhite et al. 2004). To explore mechanisms limiting elk population density and growth rates, we regressed elk population growth rate vs. wolf kill rate of elk from 1986 to 2000 while controlling for effect of snow depth (Hebblewhite et al. 2002) in the high-wolf area.

\section{Elk density and survival}

Elk populations were surveyed by helicopters under optimal snow conditions for sighting during late winter from 1986 to 2000 (Parks Canada, unpublished data). Aerial counts closely matched mark-recapture estimates (Woods 1991). Sightability models (Hebblewhite 2000 ) suggested that only $\sim 11 \%$ of the population was missed during surveys because elk congregate in large herds in open grasslands during this time in BNP. We converted counts to densities based on square kilometers in the two treatment areas. Elk pellets were counted in aspen plots (see Methods: Aspen) as an independent measure of elk density.

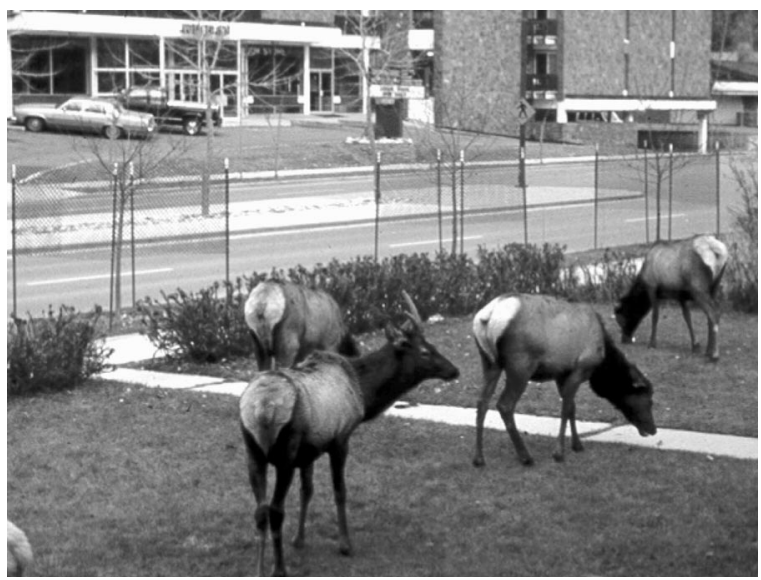

Plate 1. Elk in the low-wolf treatment area surrounding the town of Banff benefited from reduced wolf predation rates, enjoyed higher survival and calf recruitment, and achieved higher densities over the period wolves were excluded from this area. Higher elk densities resulted in increased plant damage, visible by the hedged willow shrubs and fenced aspen stems in the background in this urban scene. Photo credit: M. Hebblewhite.

Population dynamics of vertebrate herbivores are most sensitive to adult female survival (Gaillard et al. 1998), therefore, we compared survival of adult female elk from January 1997 to December 1999 between the wolf treatments. Forty-five adult female elk were captured using corral traps or ground/aerial darting using chemical immobilization. Elk were monitored weekly throughout the study, mortalities investigated $<1$ wk after death, and cause of mortality was determined from predator-specific criteria. Annual survival rates were estimated using the modified Kaplan-Meier survival estimator under a staggered entry design (Pollock et al. 1989). We used a log rank procedure to test for differences in survival between elk captured in lowwolf vs. high-wolf areas (Pollock et al. 1989). There was low home range overlap of elk between treatments, and elk showed high fidelity to areas in which they were first captured (McKenzie 2001). We estimated survival of young of year elk using late April calf:cow ground surveys (Parks Canada, unpublished data) to index recruitment of calf elk into adult age classes.

We predicted that elk in the low-wolf area would have higher survival because of reduced predation. Other habitat differences could also influence survival in the low-wolf area as a result of improved forage quality of urban landscaping and golf courses. This habitat difference represents a potentially important "bottom-up" effect, contrary to the top-down wolf effect. Therefore, we tested for differences in forage quality using fecal nitrogen content during winter (Blanchard et al. 2003). Fecal nitrogen content is correlated with dietary protein intake and may be linked to survival and weight gain in ungulates (Blanchard et al. 2003). However, use of fecal nitrogen has been crit- 


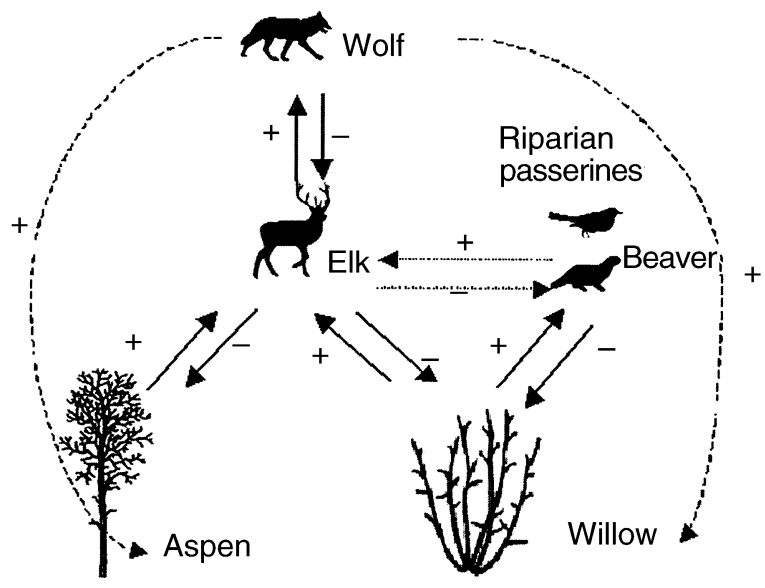

FIG. 1. Simplified trophic interactions model of the Bow Valley of Banff National Park, Alberta, Canada. Solid lines represent direct consumer-resource interactions: + for effect on upper trophic level, - for negative effect. Indirect effects are shown with dashed lines and represent an indirect displacement of wolves by human activity and indirect (exploitative) competition between herbivore levels.

icized in complex diets high in non-graminoids (Hobbs 1987). Because summer diets between treatments were expected to differ the most due to high forbs in the diet of high-wolf area elk (Woods 1991), we only compared winter fecal nitrogen between elk in low- and highwolf areas. Moreover, differences in fecal $\mathrm{N}$ are generally more important during winter when dietary $\mathrm{N}$ is limiting (Cook 2002). We estimated fecal nitrogen content during February and March 1998 using the Kjeldahl method. Total nitrogen content, expressed as a percentage of total mass, was compared using an unequal-variance $t$ test.

\section{Aspen}

We sampled from blocks of aspen stands in the Bow Valley during spring and summer 1997-1999. Plots were stratified within aspen stands for tree cover class, a primary determinant of aspen sapling regeneration (Peterson and Peterson 1992). We sampled 10 plots in four tree cover classes to control for canopy closure: stands recently $(<25$ y) disturbed $(>75 \%$ tree mortality) by fire, wind, insects, or cutting; stands with low stem density ( $<750$ stems/ha); stands with moderate stem density (750-1500 stems/ha); or stands with high tree density ( $>1500$ stems/ha). Because of a lack of full treatment combinations in individual aspen stands, some stands had several treatment plots sampled within each (White et al. 2003). In each plot, all aspen stems were counted using a $2 \times 30 \mathrm{~m}$ belt transect and placed into size classes. We estimated the percentage of browsed aspen in saplings $>1 \mathrm{~m}$ in height, but $<5 \mathrm{~cm}$ in diameter at breast height, because these are the size classes most heavily fed on by elk (White et al. 2003). Elk pellet density was recorded by counting pellet groups within two $2 \times 200 \mathrm{~m}$ belt transects oriented diagonally across dominant slopes within each plot. Differences in aspen sapling density and aspen browse intensity were analyzed using a Generalized Linear Model (McCullough and Nelder 1989) on tree cover class and the two wolf treatment areas. Nonnormal data were log- or ln-transformed where necessary to meet parametric statistical assumptions. Differences between areas for the dependent variable were reported after effects of canopy closure were controlled if canopy class was included in the final model; when canopy class was unimportant, we report just effects of area on dependent variables.

\section{Willow}

Willow sampling was conducted in 1996 and 1997. Sampling was stratified across a gradient of low vs. high beaver activity and low vs. high elk browse intensity. At least three sites were sampled for each of these four treatments. Previous analyses suggested that elk density had a much stronger effect on willow growth than did beavers (Nietvelt 2001). We examined willow herbivory in 15 sample sites in the high- and low-wolf areas. Within each site, we sampled willow browse intensity, twig biomass removal (equivalent to plant damage), and willow productivity (current annual growth [CAG], i.e., leader length) in homogenous willow stands using two randomly placed $90-\mathrm{m}$ transects at each site. Ten 1-m radius plots were sampled along each $90-\mathrm{m}$ transect for a total of 20 plots per site. We measured the diameter (millimeter) of 12 browsed twigs/plot ( $n=240 /$ site; Singer et al. 1994). Willow twig biomass (grams) removal was estimated using predictive regression equations between twig diameter at browse point vs. measured twig biomass, with $R^{2}$ values of 0.89 (Nietvelt 2001). Willow biomass production was measured during fall 1997. Current annual growth (CAG) was measured with 12 twigs/plot ( $n=240 /$ site), and biomass (grams per square meter) estimated following Singer et al. (1994). We then calculated net production as production-removal in grams per square meter. We compared current annual growth (CAG), biomass removal, and net production between the highand low-wolf areas using $t$ tests. Browse intensity and biomass removal were compared in both 1996 and 1997, and then pooled if there were no differences. CAG production was only measured in fall 1997.

\section{Beaver}

No comparative data exist for beaver densities between wolf treatments in the Bow Valley. However, to test for potential trophic interactions between elk and beaver, we explored the relationship between active beaver lodge and elk density within the Vermillion Lakes wetland $\left(3.5 \mathrm{~km}^{2}\right.$ area) in the low-wolf area. The Vermillion Lakes wetlands are the largest wetlands within BNP, and eight beaver lodge censuses were carried out from 1986 to 2000 . We tested for a relationship between the number of active beaver lodges and elk 
density in the low-wolf area using linear regression. Nietvelt (2001) explores beaver-elk interactions in more detail.

\section{Riparian songbirds}

We compared riparian songbird abundance, diversity, and evenness between areas within the riparian willow communities sampled above by recording the number of singing males between 05:00 and 09:00 hours in 50- and 100-m radii point counts (Ralph et al. 1993) during June 1999. We placed 1-point count station in different riparian willow habitat patches, sampling 6- and 4-point counts in the high- and low-wolf predation treatments. This sampling intensity represents $\sim 0.35 \mathrm{~km}^{2}$ out of $10 \mathrm{~km}^{2}$ in the study area (Holland and Coen 1983). Points were also stratified by willow height (Nietvelt 2001), but we report only areaspecific differences for the trophic cascade test. Within each area, we calculated average diversity using the Shannon-Weiner index and evenness (Krebs 1989). Treatment means were compared with unequal-variance $t$ tests for diversity, evenness, and abundance.

\section{Trophic cascade hypothesis}

We tested the trophic cascade hypothesis for the generalized trophic model for the Bow Valley of BNP illustrated in Fig. 1 where humans, wolves, elk, aspen, willow, and riparian songbirds represent a simplified trophic interactions model (see also Smith et al. 2003). The trophic cascade hypothesis makes predictions for different trophic levels in a predator exclusion/removal experiment (Polis and Strong 1996). Predator exclusion should result in reduced predator rates, leading to increased density, survival, and recruitment/growth of herbivores. These are direct effects of wolf removal. Plant damage indices, such as browse removal or percentage of browse should also be higher in predator exclusion areas, whereas vegetation productivity and survival should be reduced. Impacts of wolf removal on vegetation are indirect effects of predation (dashed lines in Fig. 1). We would also expect to see indirect effects on species that rely on abundant vegetation, i.e., riparian songbirds or beavers. Effects should alternate between adjacent trophic levels. Predictions of the trophic cascade hypothesis for each dependent variable in response to partial predator exclusion are summarized in Table 1.

To test the trophic cascade hypothesis, we used the response ratio $X_{\mathrm{e}} / X_{\mathrm{c}}$ (following Schmitz et al. 2000), where $X_{\mathrm{e}}$ is the variable of interest (abundance, biomass, survival, etc.) in the experimental predator reduction, and $X_{\mathrm{c}}$ is the same variable that is in the control area with predators present. If herbivore density increases in the low-wolf treatment, then the log response ratio would be positive. The log of the response ratio has several attractive statistical properties; foremost among these is that it reflects the proportional change in species abundance (Osenberg et al. 1997, Hedges et al. 1999). We calculated log response ratios for each variable, and estimated standard error on the log response ratio using the delta method. Finally, we calculated average trophic level responses by averaging the log response ratio for all herbivore and vegetation growth parameters to examine relative strengths of direct and indirect effects (Polis and Strong 1996).

In time series of predator removal experiments, the last time series point is usually used to compare effect sizes at steady state (Schmitz et al. 2000), or divided by time with time-varying response ratios, such as with rates (Osenberg et al. 1997). For some trophic levels, we sampled only at the end of the time series, which we assumed approximated steady state conditions (i.e., for elk survival, willow, aspen, and songbirds). For parameters for which we had time series data (i.e., for elk density, elk recruitment, and wolf kill rates), we tested for a trend in the log response ratio over time to test if responses were in steady state (Osenberg et al. 1997). If responses were not constant, we report trends in the log response ratio between high- and lowwolf areas using regression: If constant, we compared effect sizes using mean effect. Reducing complex ecological interactions to simple measures with or without predators in large-scale natural experiments may mask potentially confounding factors. Therefore, we discuss previously published mechanisms from related studies to shed insight on trophic interactions.

\section{RESULTS}

\section{Wolf predation}

Total predation rates of elk (elk killed/day) were more than twice as high in the high-wolf area compared with the low-wolf area over the entire time series $\left(t_{4,6}\right.$ $=3.63, P=0.001, \log$ response ratio $=-0.46$; Table 1). Examination of the trend in log response ratio over time indicates that the difference between treatment and control areas was not constant. The difference in predation rates decreased linearly over time (Fig. 2), indicating that maximum differences occurred at the beginning of wolf recolonization, not the end. Predation rates by wolves had a significant effect on elk population growth rates, while controlling for effects of snow depth (partial regression $Y=-2.5 \times$ (elk kill rate) $+0.235, F_{1,6}=9.0, P=0.02, R^{2}=0.55$; Fig. 3 ). Thus, increasing wolf predation reduced elk population growth rates in areas where wolves recolonized.

\section{Elk}

By the end of the study period, elk density was significantly higher in the low-wolf treatment (Table 1) by a factor of 10 . Similar to predation rates, densities diverged between areas during the study (Fig. 2), yet the trend in $\log$ response ratio for elk density reveals the largest differences late in wolf recolonization. Elk survival rates were consistent with these population trends; elk survival was significantly higher in the low- 
TABLE 1. Natural experimental comparison of the effects of partial wolf exclusion on trophic dynamics in Banff National Park, Alberta, Canada.

\begin{tabular}{|c|c|c|c|c|c|c|c|c|c|}
\hline \multirow[b]{2}{*}{ Parameter, by trophic level } & \multirow[b]{2}{*}{$N$} & \multirow{2}{*}{$\begin{array}{l}\text { Predicted } \\
\text { response }\end{array}$} & \multicolumn{2}{|c|}{$\begin{array}{l}\text { Low-wolf } \\
\text { area }\left(X_{\mathrm{e}}\right)\end{array}$} & \multicolumn{2}{|c|}{$\begin{array}{l}\text { High-wolf } \\
\text { area }\left(X_{c}\right)\end{array}$} & \multirow[b]{2}{*}{$P$} & \multicolumn{2}{|c|}{$\begin{array}{l}\text { Log response } \\
\text { ratio }\left(X_{\mathrm{e}} / X_{\mathrm{c}}\right)\end{array}$} \\
\hline & & & Mean & SE & Mean & SE & & Mean & SE \\
\hline \multicolumn{10}{|l|}{ Predator } \\
\hline Total elk killed/d & 13 & - & 0.07 & 0.01 & 0.2 & 0.03 & 0.001 & -0.46 & 0.003 \\
\hline \multicolumn{10}{|l|}{ Herbivore } \\
\hline Elk density (no. elk/km²) & 15 & + & 9.35 & 0.38 & 0.96 & 0.17 & $<0.0001$ & 0.99 & 0.063 \\
\hline Adult female elk survival & 45 & + & 0.89 & 0.06 & 0.62 & 0.06 & 0.002 & 0.16 & 0.009 \\
\hline Calf:cow recruitment ratio (\%) & 14 & + & 27.4 & 1.58 & 14.6 & 1.97 & 0.003 & 0.27 & 0.035 \\
\hline $\begin{array}{l}\text { Fecal nitrogen ( } \% \text { of total } \\
\text { mass) }\end{array}$ & 113 & $\mathrm{~N} / \mathrm{A} \dagger$ & 1.73 & 0.03 & 1.4 & 0.03 & 0.001 & 0.09 & 0.002 \\
\hline $\begin{array}{l}\text { Elk pellet density (no. pellets/ } \\
\text { ha) in aspen }\end{array}$ & 90 & + & 7.91 & 1.1 & 2.54 & 0.39 & $<0.001$ & 0.49 & 0.007 \\
\hline \multicolumn{10}{|l|}{ Vegetation } \\
\hline $\begin{array}{l}\text { Aspen recruitment (no. } \\
\left.\text { saplings } / 100 \mathrm{~m}^{2}\right) \ddagger\end{array}$ & 90 & - & 2.25 & 1.18 & 5.87 & 1.92 & 0.21 & -0.42 & 0.247 \\
\hline Aspen browse intensity (\%) & 90 & + & 77 & 4.1 & 65 & 5.2 & 0.18 & 0.07 & 0.011 \\
\hline Willow CAG $\left(\mathrm{g} / \mathrm{m}^{2}\right)$ & 15 & 0 & 61.5 & 2.39 & 43.12 & 3.32 & 0.32 & 0.15 & 0.019 \\
\hline Willow browse removed $\left(\mathrm{g} / \mathrm{m}^{2}\right)$ & 15 & + & 56.5 & 3 & 6.98 & 1.18 & 0.0001 & 0.91 & 0.061 \\
\hline $\begin{array}{l}\text { Willow net browse production } \\
\left(\mathrm{g} / \mathrm{m}^{2}\right)\end{array}$ & 15 & - & 5 & 2.5 & 36.98 & 2.4 & 0.01 & $-\mathbf{0 . 8 7}$ & 0.213 \\
\hline \multicolumn{10}{|l|}{ Songbird } \\
\hline Songbird diversity & 10 & - & 5.17 & 0.53 & 10.51 & 1.05 & 0.04 & -0.31 & 0.002 \\
\hline Evenness & 10 & - & 0.93 & 0.03 & 0.95 & 0.008 & 0.27 & -0.01 & 0.013 \\
\hline Abundance & 10 & - & 9.5 & 1.14 & 17.25 & 1.8 & 0.014 & -0.26 & 0.010 \\
\hline
\end{tabular}

Notes: Shown are trophic parameters tested, their predicted response to partial wolf exclusion under the trophic cascade hypothesis, the response in the partial-exclusion area $\left(X_{\mathrm{e}}\right)$, and the response in the adjacent control area where wolves were present throughout the study $\left(X_{\mathrm{c}}\right)$. Presented are the sample size $(N)$, the mean parameter $(X)$ value compared with or without wolves, SE, $P$ values from the corresponding statistical test ( $t$ test, GLM, etc.) between treatment means, the log response ratio $\left[\log \left(X_{\mathrm{e}} / X_{\mathrm{c}}\right)\right]$, and SE of the $\log$ response ratio. Positive $\log$ response ratio values indicate that the parameter was greater with partial wolf exclusion; negative values indicate that the parameter was greater in the control. Log response ratios in boldface are significant at $P=0.05$. Calf:cow ratio, wolf kill rates, total number of elk killed, and elk density were all time series; thus, the $\log$ response ratio is the average of $\Sigma\left(X_{\mathrm{e}} / X_{\mathrm{c}}\right)$ over all $i$, where $i=1 \ldots n$, and $n$ are the years of observation. $\mathrm{CAG}$ is an abbreviation for current annual growth.

$\dagger$ Under the trophic cascade hypothesis, there is no predicted difference in fecal $\mathrm{N}$ between treatments. Fecal $\mathrm{N}$ was compared to explore potential bottom-up effects of habitat differences between treatments.

\$ Saplings $/ 100 \mathrm{~m}^{2}$ where saplings are $>1 \mathrm{~m}$ in height, but $<5 \mathrm{~cm}$ dbh (see Methods: Aspen for details).

wolf area $(0.89 \pm 0.09$ [mean $\pm \mathrm{SE}])$ compared with the high-wolf area $(0.62 \pm 0.1)$ from 1997 to $1999(\log$ rank test $P=0.002$; Table 1$)$. Wolf predation was responsible for $44 \%(n=6)$ of all radiocollared female elk mortality, and $75 \%$ of elk mortality not arising due to vehicular accidents (McKenzie 2001). In contrast to elk density, the log response ratio for calf recruitment between high and low-wolf treatments showed no trends in log response ratios (Fig. 2). Thus, the magnitude of the effect of wolves on calf recruitment was constant over the study period. Therefore, we compared average calf recruitment using unequal-variance $t$ tests. Elk calf recruitment was significantly higher in the lowwolf area; just less than double, on average $\left(t_{13,15}=\right.$ 3.308, $P=0.003$; Table 1). Elk fecal nitrogen was significantly higher during winter months for elk in the low-wolf area than in the high-wolf area $(P<0.001$; Table 1). In aspen plots, elk pellet density was 3.2 times higher in the central no-wolf area (no effect of cover class $P=0.463$, effect of area, $F_{1,85}=25.22, P<$ 0.0001; Table 1).

\section{Aspen}

We sampled a total of 52 aspen plots in high-wolf areas, and 32 in low-wolf areas during 1997-1999. During 1997-1999, there was a strong effect of aspen cover type on sapling density. As predicted, more recently disturbed sites had much higher sapling density than did older sites, although all other cover classes had similar sapling densities $\left(F_{3,85}=3.68, P=0.015\right)$. After correcting for differences between cover class, there were approximately double the sapling densities in the high-wolf area than in the low-wolf areas (Table 1 ), but this difference was not statistically significant by $1999\left(F_{1,85}=1.3, P=0.21\right)$. Browsing on aspen was unaffected by cover type $\left(F_{3,85}=1.05, P=0.37\right)$, and while higher in the low-wolf than the high-wolf treatment, this difference was not statistically significant by $1997-1999\left(F_{1,85}=1.66, P=0.18\right.$; Table 1$)$.

\section{Willow}

There were no differences between years in browse intensity (Neitvelt 2001), so we grouped these data. 


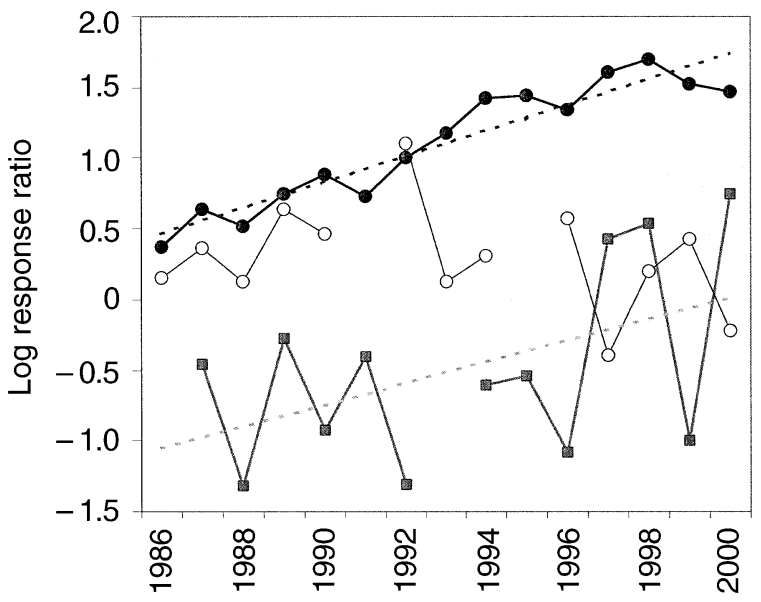

FIG. 2. Time series of the log response ratio between the exclusion treatment $\left(X_{\mathrm{e}}\right.$, low-wolf area) and control $\left(X_{\mathrm{c}}\right.$, highwolf area) for elk density (solid circles), spring calf:cow recruitment ratio (open circles), and wolf kill rate of elk (gray squares) in Banff National Park from 1986 to 2000. Dashed lines represent general linear regression trends during the study, and missing values are indicated by breaks. There was no significant trend in calf:cow ratio, indicating stationary trophic effects of wolves on calf:cow ratio. Log response ratio values above zero represent higher responses in the partial wolf-exclusion area, $X_{\mathrm{e}}$ (i.e., higher elk densities), whereas values below zero represent higher responses in the control area, $X_{\mathrm{c}}$ (i.e., higher wolf kill rates).

Browse intensity was, on average, seven times higher in the low-wolf area $\left(t_{12,17}=12.07, P=0.0001\right.$; Table $1)$. Browse removal was eight to nine times greater in the low-wolf area than in the high-wolf area $\left(t_{4,6}=\right.$ 2.93, $P=0.012)$. Current annual growth production did not differ, however, between treatments $\left(t_{4,6}=1.05\right.$, $P=0.32$; Table 1), emphasizing that differences between areas were due to herbivory and not site productivity or moisture regimes. Despite similar production, the impact of high twig removal resulted in significant net differences between areas $\left(t_{4,6}=3.06, P=\right.$ 0.01 ; Table 1) with net production over seven times higher in the presence of wolf predation.

\section{Beaver and riparian songbirds}

The number of active beaver lodges in the low-wolf treatments at Vermillion Lakes wetland declined over time with increasing elk density (number of active beaver lodges $=-0.73 \times\left(\right.$ no. elk $\left./ \mathrm{km}^{2}\right)+9.14, F_{1,6}=$ 26.15, $P=0.002, R^{2}=0.81$; Fig. 4$)$. We detected a total of 22 different songbird species on surveys, and counted a total of 126 singing males. Riparian songbird abundance $\left(t_{4,6}=3.63, P=0.014\right)$ and diversity $\left(t_{4,6}\right.$ $=3.00, P=0.04)$ decreased in riparian willow in the low-wolf area (with abundance and diversity approximately double in areas with wolves; Table 1). Evenness, however, did not differ between areas with and without wolf predation $\left(t_{4,6}=1.21, P=0.27\right.$; Table 1). Species that were not detected in low-wolf areas were American Redstart (Setophaga ruticilla), Tennes- see Warbler (Vermivora peregrina), Orange-crowed Warbler (V. celata), and Least Flycatcher (Empidonax minimus) (Nietvelt 2001).

\section{DISCUSSION}

Recolonization of wolves had substantial direct effects on elk demography in BNP, reducing elk density, survival, and recruitment. Indirect effects of wolf recolonization on vegetation and animal communities were also consistent with the trophic cascade hypothesis, representing one of the first experimental tests across trophic levels in a large-scale terrestrial system. All predictions made by the trophic cascade hypothesis were supported (Table 1). Increased wolf predation, in combination with winter severity (Hebblewhite et al. 2002), was a principal factor responsible for differences in elk density between areas (Fig. 3). Predator exclusion because of high human activity reduced predation rates by wolves by $>60 \%$ (Table 1 ), which resulted in increased elk density, adult and calf survival, and elk pellet density. Wolf exclusion also had substantial negative indirect effects on vegetation productivity (Table 1). Plant damage indices (percentage of browse, biomass removed) increased with wolf removal, consistent with predictions of the cascade hypothesis. Finally, wolf exclusion indirectly reduced songbird diversity and abundance but not evenness, suggesting the mechanism influencing bird diversity was not through species dominance, but changes in species composition (Berger et al. 2001).

Effect sizes were consistent with those from other published studies from terrestrial trophic cascades (Schmitz et al. 2003). Average direct effect strength of wolves on elk was $\sim 1.25$ (average of elk responses; Table 1). Average indirect effect strength of wolves on vegetation growth parameters was much weaker ( -0.65 ; Table 1). Direct effects of predator reduction

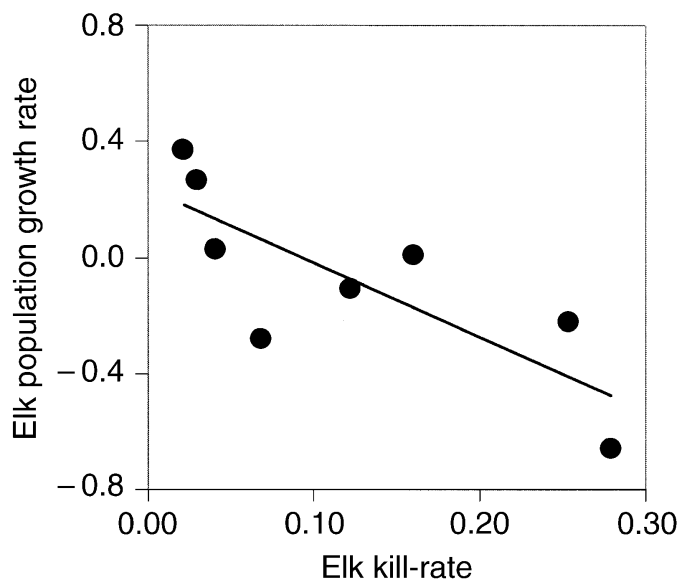

FIG. 3. Relationship between elk population growth rate $\left(r_{t}=\ln \left[N_{t+1} / N_{t}\right]\right)$ and elk-kill rate (no. elk killed/day/pack) in the Bow Valley of Banff National Park area with wolf predation from 1986 to 2000. 


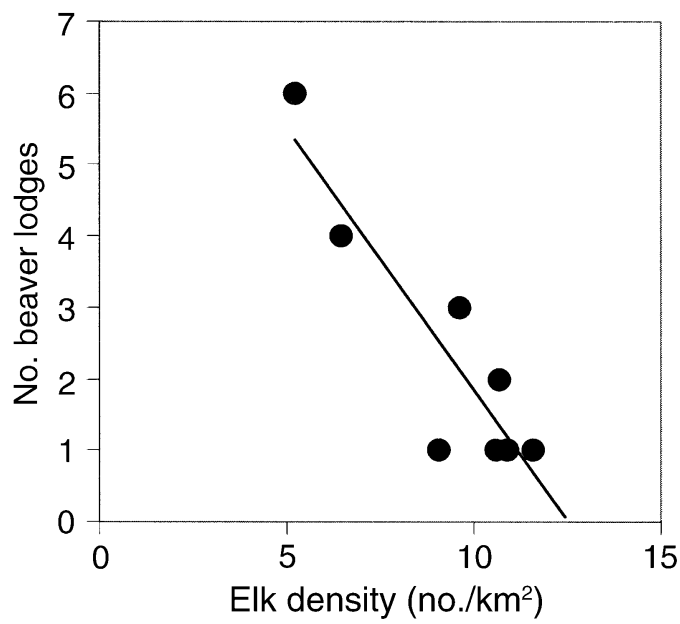

FIG. 4. Number of active beaver lodges within the lowwolf treatment area's dominant wetlands, the Vermillion Lakes wetlands, as a function of central area (no-wolf) elk density in Banff National Park from 1986 to 2000.

on herbivores ranged from 0.4 to 2.87 in the studies reviewed by Schmitz et al. (2000), whereas indirect effect strength on plants ranged from -0.25 to -3.58 . The ratio of absolute direct to indirect effects tests whether predation effects attenuate at lower trophic levels. If the response ratio is $>1$, then predation effects attenuate and grow weaker on lower trophic levels such as plants, whereas if the response ratio $<1$ then predation effects intensify (Polis and Strong 1996). The ratio of average direct to indirect effects in our system was $1.92(1.25 / 0.65=1.92,>1)$ suggesting that predation effects attenuate and are weaker on lower trophic levels, consistent with literature reviews (Polis and Strong 1996, Schmitz et al. 2000). Thus, direct wolf predation effects on elk seem stronger than indirect effects of predators on plants. While recent studies have suggested behavioral avoidance of high-wolf predation risk areas by elk may be an important indirect effect (Fortin et al. 2005), our analysis is the first comparative evidence that direct effects of wolf predation on trophic dynamics may be more important than indirect behaviorally mediated effects.

Subsequent effects of differential predation on elk survival are consistent with the emerging literature on ungulate population dynamics (Gaillard et al. 1998). Adult and calf elk survival was lower in areas with high predation, and wolves caused a large proportion of elk mortality (44\%). However, at least some of the increase in elk survival in the low-wolf area could be due to improved nutritional quality of elk diets (Table 1) due to fertilization and introduced species (McKenzie 2001). Regardless of this potential bottom-up effect, we believe the strength of the top-down trophic evidence of wolves suggests that bottom-up influences were minimal.
Elk survival differences translated into differences in herbivory intensity on dominant deciduous plants (Table 1). Willows had stronger indirect responses to reduction in wolf predation than aspen. This may be related to higher preference for aspen by elk during winter (Hobbs et al. 1981), the spatial arrangement of aspen patches (Wallace et al. 1995), or temporal lag effects. Although not statistically significant, the doubling in aspen sucker recruitment with wolf predation (Table 1) indicated that many aspen stands were successfully regenerating with wolf predation, and that other factors, such as disturbance, were interacting (White et al. 2003). While the main study ended in 2001, preliminary aspen recruitment data collected during 2003 in the high-wolf area support our interpretation of a time lag in aspen response. Aspen sapling recruitment had increased from $5.87 \mathrm{stems} / 100 \mathrm{~m}^{2}$ in 1999 (Table 1) to 9.93 stems $/ 100 \mathrm{~m}^{2}$ in 2003 , suggesting a delay in recruitment. While we do not have aspen recruitment in the low-wolf area for 2003, assuming similar recruitment to 1999 (i.e., 2.2 stems/100 $\mathrm{m}^{2}$; Table 1) because elk densities have remained stable (Parks Canada, unpublished data), aspen recruitment may have approached statistical significance by 2003. Studies of aspen across the Canadian Rocky Mountains (White et al. 2003) show that elk densities must fall below $1 \mathrm{elk} / \mathrm{km}^{2}$ before aspen regeneration occurs. Similar demographic studies on willows suggest that less than $\sim 5 \mathrm{elk} / \mathrm{km}^{2}$ are required for willow regeneration (Neitvelt 2001).

Mechanisms underlying potential elk competition with beaver include exploitative competition for willow (Nietvelt 2001). With increasing elk density, competition would increase between beaver and elk for tall willow, possibly leading to beaver declines because of insufficient willow (Singer et al. 1994, Nietvelt 2001). As perhaps the penultimate keystone species, declining beaver density could have important impacts on biodiversity and ecosystem structure and function (Naiman et al. 1986). Similar to Berger et al.'s (2001) more extensive sampling, we found declines in neotropical migrant abundance and diversity in areas heavily browsed by elk (Table 1), especially by obligate willow specialists such as the American Redstart. Mechanisms behind the indirect effect of wolf predation on songbirds may arise either by direct lethal effects reducing elk density and willow herbivory, or alternately, by wolf predation on elk releasing beaver from exploitative competition by elk.

The results of previous independent studies on individual links in our trophic model (Fig. 1) support our findings. Previous work showed that predation by wolves can have strong limiting and even regulatory effects on nonmigratory ungulate populations (Messier 1994, Hebblewhite et al. 2002). Aspen and willow responses to elk herbivory have been well documented in similar environments. Recent research in Rocky Mountain National Park, USA, suggests that elk her- 
bivory can limit willow abundance and distribution (Zeigenfuss et al. 2002), and research in Yellowstone National Park (YNP), USA, indicates that predation by recolonizing wolves may be stimulating aspen (Ripple et al. 2001) and cottonwood (Populus balsamifera) regeneration (Ripple and Beschta 2003). Berger et al. (1999) have convincingly shown that songbird diversity and abundance declines with increasing moose herbivory in Wyoming. Recent evidence even suggests the potential for geochemical trophic cascades by recolonizing wolves in YNP (Garrott et al. 2002). Thus, our research is consistent with the results of individual studies focusing on individual components of the food web envisioned in Fig. 1 (see also Smith et al. 2003) that suggest wolf-mediated trophic cascades should exist.

As with any large-scale natural experiment, however, our study has its limitations. We report only on differences resulting from partial wolf exclusion, despite a diverse large carnivore guild. High human use also excluded other predators such as grizzly bears from the low-wolf area during this study (Gibeau et al. 2002). This important caveat suggests that other predators may also be implicated to unknown degree in the observed cascade effect. However, we still believe that most of the trophic cascade was a direct result of wolf predation for two reasons. First, wolves were the only carnivores to recover from extirpation in the study area during this period (Paquet et al. 1996), whereas bears and other predators were never completely eliminated. Second, cause-specific mortality of elk (McKenzie 2001) and time series modeling (Hebblewhite et al. 2002) support the major role of wolves in the trophic cascade. Also, effects would likely have been even greater, had predators been completely excluded, as suggested by aspen and willow exclosure experiments (Nietvelt 2001, White 2001). Therefore, we believe our results illustrate a trophic cascade largely caused by predation by recolonizing wolves, and of key management importance is that human exclusion of wolves made detection of this trophic cascade possible. Therefore, human exclusion of wolves and other large predators may seriously impact ecosystem dynamics. In conclusion, conservation and management plans based on the trophic importance of large carnivores (Terborgh et al. 1999, Carroll et al. 2001) such as wolves have increased support in terrestrial systems.

\section{ACKNOWLEDGMENTS}

We thank financial support from Parks Canada, the Central Rockies Wolf Project, John/Paul and Associates, Human Resources Development Canada, Alberta Enhanced Career Development, Alberta Sustainable Resource Development, Canadian Pacific Foundation, the Canadian Wildlife Foundation, Shell Environment Fund, the Paquet Wildlife Fund, World Wildlife Fund-Canada, and Patagonia. We thank strong logistical support from the Banff Warden Service, Central Rockies Wolf Project, and field assistants and technicians too numerous to count; without their help and long-term commitment, this large-scale collaborative study would not have been possible. Advice from M. Feller, C. Pacas, A. R. E. Sinclair, C. Kay, and D. H. Pletscher helped study design and interpretation. We thank constructive reviews by R. Moen, S. Seagle, and one anonymous reviewer that greatly improved the manuscript. Finally, a Canon-National Parks Service Science Scholarship for the Americas' supported the senior author, M. Hebblewhite, during analyses and preparation of the manuscript.

\section{Literature Cited}

Berger, J., P. B. Stacey, L. Bellis, and M. P. Johnson. 2001. A mammalian predator-prey disequilibrium: how the extinction of grizzly bears and wolves affects the diversity of avian neotropical migrants. Ecological Applications 11: 947-960.

Blanchard, P., M. Festa-Bianchet, J.-M. Gaillard, and J. T. Jorgenson. 2003. A test of long-term fecal nitrogen monitoring to evaluate nutritional status in bighorn sheep. Journal of Wildlife Management 67:477-484.

Carpenter, S. R., J. M. Kitchell, and J. R. Hodgson. 1985. Cascading trophic interactions and lake productivity. Bioscience 35:634-639.

Carroll, C., R. F. Noss, and P. C. Paquet. 2001. Carnivores as focal species for conservation planning in the Rocky Mountain region. Ecological Applications 11:961-980.

Cook, R. G. 2002. Nutition and food. Pages 259-350 in D. E. Toweill and J. W. Thomas, editors. North American elk: ecology and management. Smithsonian Institution Press, Washington D.C., USA.

Duke, D. L., M. Hebblewhite, P. C. Paquet, C. Callaghan, and M. Percy. 2001. Restoration of a large carnivore corridor in Banff National Park. Pages 261-275 in D. S. Maehr, R. F. Noss, and J. L. Larkin, editors. Large mammal restoration: ecological and sociological challenges in the $21 \mathrm{st}$ century. Island Press, Washington D.C., USA.

Fortin, D., H. Beyer, M. S. Boyce, D. W. Smith, T. Duchesne, and J. S. Mao. 2005. Wolves influence elk movements: behavior shapes a trophic cascade in Yellowstone National Park. Ecology 86, in press.

Fritts, S. H., E. E. Bangs, J. A. Fontaine, M. R. Johnson, M. K. Phillips, E. D. Koch, and J. R. Gunson. 1997. Planning and implementing a reintroduction of wolves to Yellowstone National Park and central Idaho. Restoration Ecology 5:7-27.

Gaillard, J.-M., M. Festa-Bianchet, and N. G. Yoccoz. 1998. Population dynamics of large herbivores: variable recruitment with constant adult survival. Trends in Ecology and Evolution 13:58-63.

Garrott, R. A., L. L. Eberhardt, J. K. Otton, P. J. White, and M. A. Chaffee. 2002. A geochemical trophic cascade in Yellowstone's geothermal environments. Ecosystems 5: 659-666.

Gibeau, M. L., A. P. Clevenger, S. Herrero, and J. Wierzchowski. 2002. Grizzly bear response to human development and activities in the Bow River Watershed, Alberta, Canada. Biological Conservation 103:227-236.

Hebblewhite, M. 2000. Wolf-elk predator-prey dynamics in Banff National Park. Thesis. University of Montana, Missoula, Montana, USA.

Hebblewhite, M., P. C. Paquet, D. H. Pletscher, R. B. Lessard, and C. J. Callaghan. 2004. Development and application of a ratio-estimator to estimate wolf killing rates and variance in a multiple prey system. Wildlife Society Bulletin 31:933-946.

Hebblewhite, M., D. H. Pletscher, and P. C. Paquet. 2002. Elk population dynamics in areas with and without predation by recolonizing wolves in Banff National Park, Alberta. Canadian Journal of Zoology 80:789-799.

Hedges, L. V., J. Gurevitch, and P. S. Curtis. 1999. The metaanalysis of response ratios in experimental ecology. Ecology 80:1150-1156. 
Hobbs, N. T. 1987. Fecal indices to dietary quality: a critique. Journal of Wildlife Management 51:317-320.

Hobbs, N. T., D. L. Baker, J. E. Ellis, and D. M. Swift. 1981. Composition and quality of elk winter diets in Colorado. Journal of Wildlife Management 45:156-171.

Holland, W. D., and G. M. Coen. 1983. Ecological (biophysical) land classification of Banff and Jasper National Parks. Volume 1. Summary. Alberta Institute of Pedology, Edmonton, Alberta, Canada.

Holroyd, G. L., and K. J. Van Tighem. 1983. Ecological (biophysical) land classification of Banff and Jasper National Parks. Volume 3. The wildlife inventory. Canadian Wildlife Service, Edmonton, Alberta, Canada.

Krebs, C. J. 1989. Ecological methodology. Harper Collings Publishers, New York, New York, USA.

Krebs, C. J., S. Boutin, R. Boonstra, A. R. E. Sinclair, J. N. M. Smith, R. T. Dale, K. Martin, and R. Turkington. 1995. Impact of food and predation on the snowshoe hare cycle. Science 269:1112-1118.

Lima, S. L., and L. M. Dill. 1990. Behavioral decisions made under the risk of predation: a review and prospectus. Canadian Journal of Zoology 68:619-640.

McCullough, P., and J. A. Nelder. 1989. Generalized linear models. Second edition. Chapman and Hall, London, UK.

McKenzie, J. A. 2001. The selective advantage of urban habitat use by elk in Banff National Park. University of Guelph, Guelph, Ontario, Canada.

McLaren, B. E., and R. O. Peterson. 1994. Wolves, moose and tree rings on Isle Royale. Science 266:1555-1558.

Messier, F. 1994. Ungulate population models with predation: a case study with the North American moose. Ecology 75: $478-488$.

Naiman, R. J., J. M. Melillo, and J. E. Hobbie. 1986. Ecosystem alteration of boreal forest streams by beaver (Castor canadensis). Ecology 67:1254-1269.

Nietvelt, C. N. 2001. Herbivory interactions between beaver (Castor canadensis) and elk (Cervus elaphus) on willow (Salix spp.) in Banff National Park, Alberta. University of Alberta Edmonton, Alberta, Canada.

Osenberg, C. W., O. Sarnelle, and S. D. Cooper. 1997. Effect size in ecological experiments: the application of biological models in meta-analysis. American Naturalist 150:798812.

Paine, R. T. 1969. A note on trophic complexity and community stability. American Naturalist 103:91-93.

Paquet, P. C., J. Wierzchowski, and C. Callaghan. 1996. Summary report on the effects of human activity on gray wolves in the Bow River Valley, Banff National Park. Pages 74120 in J. C. Green, C. Pacas, L. Cornwell, and S. Bayley, editors. Ecological outlooks project. A cumulative effects assessment and futures outlook of the Banff Bow Valley. Prepared for the Banff Bow Valley study. Department of Canadian Heritage, Ottawa, Ontario, Canada.

Parks Canada. 2000. "Unimpaired for future generations?" Protecting ecological integrity within Canada's National Parks. Report on the Panel on the Ecological Integrity of Canada's National Parks, Ottawa, Ontario, Canada.

Peterson, E. B., and N. M. Peterson. 1992. Ecology, management, and use of aspen and balsam poplar in the prairie provinces. Forestry Canada, Northwest Region, Special Report Number 1. Northern Forestry Centre, Edmonton, Alberta, Canada.

Polis, G. A., and D. R. Strong. 1996. Food web complexity and community dynamics. American Naturalist 147:813846.

Pollock, K. H., S. R. Winterstein, and M. J. Conroy. 1989. Survival analysis in telemetry studies: the staggered entry design. Journal of Wildlife Management 53:7-15.
Power, M. E., D. Tilman, J. A. Estes, B. A. Menge, W. J. Bond, L. S. Mills, G. Daily, J. C. Castilla, J. Lubchenco, and R. T. Paine. 1996. Challenges in the quest for keystones. Bioscience 46:609-620.

Ralph, C. J., G. R. Geupel, P. Pyle, T. E. Marine, and D. F. DeSante. 1993. Handbook of field methods for monitoring landbirds. Report number PSW-GTR-144, Pacific Southwest Research Station, Forest Service, USDA, Albany, California, USA.

Ripple, W. J., and R. L. Beschta. 2003. Wolf reintroduction, predation risk, and cottonwood recovery in Yellowstone National Park. Biological Conservation 184:299-313.

Ripple, W. J., E. J. Larsen, R. A. Renkin, and D. W. Smith. 2001. Trophic cascades among wolves, elk and aspen on Yellowstone National Park's northern range. Biological Conservation 102:227-234.

Schmitz, O. J., A. P. Beckerman, and K. M. O’Brien. 1997. Behaviorally mediated trophic cascades: effects of predation risk on food web interactions. Ecology 78:1388-1399.

Schmitz, O. J., P. A. Hämback, and A. P. Beckerman. 2000. Trophic cascades in terrestrial systems: a review of the effects of carnivore removals on plants. American Naturalist 155:141-153.

Shurin, J. B., E. T. Borer, E. W. Seabloom, K. Anderson, C. A. Blanchette, B. Broitman, D. Cooper, and S. Halpern. 2002. A cross-system comparison of the strength of trophic cascades. Ecology Letters 5:785-791.

Simberloff, D. 1998. Flagships, umbrellas, and keystones: is single-species management passé in the landscape era? Biological Conservation 83:247-257.

Singer, F. J., L. C. Mark, and R. C. Cates. 1994. Ungulate herbivory of willows on Yellowstone's northern winter range. Journal of Wildlife Management 47:435-443.

Smith, D. W., R. O. Peterson, and D. B. Houston. 2003. Yellowstone after wolves. Bioscience 53:330-340.

Soulé, M. E., and J. Terborgh, editors. 1999. Continental conservation: scientific foundations of regional reserve networks. The Wildlands Project. Island Press, Washington, D.C., USA.

Terborgh, J., J. A. Estes, P. Paquet, K. Ralls, D. Boyd-Heger, B. J. Miller, and R. F. Noss. 1999. The role of top carnivores in regulating terrestrial ecosystems. Pages 39-64 in M. E. Soulé and J. Terborgh, editors. Continental conservation: scientific foundations of regional reserve networks. The Wildlands Project. Island Press, Washington, D.C., USA. Terborgh, J., L. Lopez, P. V. Nunez, M. Rao, G. Shahabuddin, G. Orihuela, M. Riveros, R. Ascanio, G. H. Adler, T. D. Lambert, and L. Balbas. 2001. Ecological meltdown in predator-free forest fragments. Science 294:1924-1925.

Wallace, L. L., M. G. Turner, W. H. Romme, R. V. Oneill, and Y. G. Wu. 1995. Scale of heterogeneity of forage production and winter foraging by elk and bison. Landscape Ecology 10:75-83.

White, C. A., M. C. Feller, and S. Bayley. 2003. Predation risk and the functional response of elk-aspen herbivory. Forest ecology and Management 181:77-97.

White, C. C. 2001. Aspen, elk and fire in the Canadian Rocky Mountains. Dissertation. University of British Columbia, Vancouver, Canada.

Woods, J. G. 1991. Ecology of a partially migratory elk population. University of British Columbia, Vancouver, Canada.

Wright, S. J., M. E. Gompper, and B. DeLeon. 1994. Are large predators keystone species in Neotropical forests? The evidence from Barro Colorado Island. Oikos 71:279294.

Zeigenfuss, L. C., F. J. Singer, S. A. Williams, and T. L. Johnson. 2002. Influences of herbivory and water on willow in elk winter range. Journal of Wildlife Management 66: $788-795$. 